\title{
COVID-19 Crisis and Precautions in Dental Practice: A Review Report
}

\author{
Payal Kansara ${ }^{1}$, Tikal Kansara ${ }^{2}$, Arjun K Kini ${ }^{3}$, Bapanaiah Penugonda ${ }^{4}$
}

\begin{abstract}
Background: In December 2019, a new deadly, highly contagious virus, namely coronavirus disease-2019 (COVID-19) outbroke in Wuhan city, China, from wildlife trading and consumption. Till mid-February, the virus spread to almost all continents of the world with a death toll in the 1000s. As this novel coronavirus lacked specific treatment, the focus was directed on prevention.

Types of studies reviewed: As COVID-19 was new to the world, all the available literature including original articles, case reports, World Health Organization and Center for Disease Control recommendations, and various other government and nongovernment institute guidelines were reviewed to make this report.

Results: Even though dental procedures have the highest chance of transmission, there are lacked recommendations on precautions and preventing the spread of this deadly virus in dental practice. After analyzing the above available literature, we outlined recommendations on the specific cohort of patients to provide dental treatment during the COVID-19 pandemic. Additionally, we also outlined the proper use of personal protective equipment, infection control in dental practice, and a special focus on treatment during and after the COVID-19 pandemics. Dental implications: With proper knowledge and understanding of prevention in a dental setup, the chances of cross infection can be substantially reduced.

Keywords: Coronavirus, COVID-19, Dental clinic/lab, Dental practice, Dentistry, Infection control, Precautions against COVID-19, Virology. Journal of Oral Health and Community Dentistry (2021): 10.5005/jp-journals-10062-0098
\end{abstract}

\section{INTRODUCTION}

On December 31, 2019, in Wuhan city (Hubei province) in China, nearly 27 cases of pneumonia of unknown etiology were hospitalized. ${ }^{1}$ After multiple testing, the Chinese Center for Disease Control and Prevention was able to isolate the causative agent which was later termed as coronavirus disease-2019 (COVID-19) by the World Health Organization (WHO). ${ }^{2}$ Most patients had a recent history of exposure to wildlife animals at Huanan Seafood Wholesale Market in Wuhan, where poultry, snakes, bats, and other forms of animals were sold. ${ }^{3}$ The International Committee on Taxonomy of Viruses suggested this novel coronavirus name as severe acute respiratory syndrome-novel coronavirus-2 (SARS-nCoV-2) due to the phylogenetic and taxonomic analysis of this novel coronavirus. ${ }^{4}$ On January 30, 2020, WHO declared the COVID-19 outbreak as the sixth public health emergency of international concern, following H1N1 (2009), polio (2014), Ebola in West Africa (2014), Zika (2016), and the most recent of all the infamous Ebola pandemic in the Democratic Republic of Congo (2019). The COVID-19 pandemic which started in China has spread to almost every country in the world. ${ }^{2}$

\section{Review}

\section{Virology}

The novel coronavirus, 2019-nCoV, is the seventh member of the family of coronavirus that infects humans, after Middle East respiratory syndrome coronavirus (MERS-nCoV) and severe acute respiratory syndrome coronavirus (SARS-nCoV). COVID-19 is a $\beta$-coronavirus of group $2 \beta$ with $70 \%$ similarity in genetic sequence to SARS-nCoV. ${ }^{5}$ The source of new coronavirus infection has been
${ }^{1}$ New York University College of Dentistry, New York, United States of America

${ }^{2}$ Department of Medicine, New York Medical College, Metropolitan Hospital Center, New York, United States of America

${ }^{3}$ Department of Conservative Dentistry and Endodontics, 7W Comprehensive Clinic, New York University College of Dentistry, New York, United States of America

${ }^{4}$ Department of Cariology and Comprehensive Care, New York University College of Dentistry, New York, United States of America

Corresponding Author: Arjun K Kini, Department of Conservative Dentistry and Endodontics, 7W Comprehensive Clinic, New York University College of Dentistry, New York, United States of America, Phone: +919844000030, e-mail: arjun.kini9@gmail.com

How to cite this article: Kansara P, Kansara T, Kini AK, et al. COVID-19 Crisis and Precautions in Dental Practice: A Review Report. J Oral Health Comm Dent 2021;15(2):78-83.

Source of support: Nil

Conflict of interest: None

determined as bats. With a full-length genome sequence, 2019-nCoV is $96 \%$ identical at the whole-genome level to a bat coronavirus. ${ }^{6}$

\section{Epidemiology}

Cases are usually large in number, occur in a constant rising frequency, and spread rapidly all around the world. ${ }^{5}$ According to the daily report of $\mathrm{WHO}$, the epidemic registered 5,952,145 cases worldwide and 365,437 reported deaths as of May 30, 2020.

The United States became a new epicenter for coronavirus pandemic with registered cases of 1,784,793 and 104,186 deaths by May 30, 2020.? 


\section{Transmission}

Based on the genetic and epidemic research, it was found that the transmission started from animal to human followed by a sustained human-to-human spread. ${ }^{8}$ The most common transmission routes of novel coronavirus include direct transmission in the form of cough, sneeze, and droplets, inhalation transmission, and contact transmission consisting of contact with oral, nasal, and eye mucus membranes. ${ }^{8}$ Besides, there exists a risk for fecal-oral with the pathogen being found in the feces of patients in the United States. ${ }^{9}$

\section{Clinical Features}

Most patients are in the age-group between 30 and 79 years. The median age ranges from 49 to 59 years. ${ }^{10}$ Clinical presentation varies from asymptomatic infection to severe respiratory failure. According to the Center for Disease Control (CDC), the main symptoms develop 2-14 days after exposure, that consist of fever, cough, and shortness of breath. The uncommon symptoms include diarrhea, sputum production, headache, and hemoptysis. The critical warning signs for novel coronavirus infection include persistent pain or pressure in the chest, trouble breathing, new confusion or inability to arouse, and bluish lips or face. ${ }^{11}$ As per $\mathrm{WHO}$, the most common symptoms are fever, tiredness, and dry cough, and the less common symptoms are shortness of breath, aches and pains, and sore throat, and very few people report diarrhea, nausea, and runny nose. ${ }^{12}$

A recent study in France conducted by Chaux-Bodard et al. observed certain cutaneous lesions caused by the SARS-CoV-2 virus which could be a result of vasculitis as the virus is known to elicit or induce a vascular inflammation. The case showed a 45-year-old female patient, who presented with an irregular ulcer on the dorsal surface of her tongue. The history of the lesion revealed a 24-hour painful inflammation of the tongue papilla followed by a 24-hour erythematous macula which evolved into an asymptomatic ulcer that healed completely in 10 days without leaving a scar. The patient also experienced general symptoms, such as mild asthenia. A COVID-19 test was performed on the 8th day, which was turned out to be positive. ${ }^{13}$

\section{Why Oral Healthcare Profession is Said to be Higher Risk for the Spread of Coronavirus?}

The live viruses were consistently present in the saliva of an infected individual as determined by the viral culture method. ${ }^{14}$ Sabino-Silva et al. $^{15}$ suggested three pathways for COVID-19 to present in the saliva: firstly, COVID-19 in the lower and upper respiratory tract enters the oral cavity with liquid droplets frequently exchanged by the respiratory and upper alimentary tracts. ${ }^{16}$ Secondly, COVID-19 present in the blood can access the mouth via the gingival crevicular fluid. ${ }^{17}$ Finally, COVID-19 enters the oral cavity by major and minor salivary gland infections which are then secreted in the saliva. Dental care setting possesses a higher risk because of the specificity of its procedure which involves face-to-face communication with patients, frequent exposure to saliva, blood, and body fluids, and handling of sharp instruments. ${ }^{18}$

As asymptomatic patients can transmit the virus, the risk of infection during dental procedures increases. The asymptomatic incubation period for individuals infected with coronavirus is 1-14 days; however, even after 24 days, the virus was detected in some asymptomatic individuals. Further, it is confirmed that those without symptoms can spread the virus. ${ }^{19}$ In a month, one infected person can transmit the virus to at least 400 people. $^{20}$
The 2019-CoV enters the cell through the angiotensinconverting enzyme 2 (ACE-2) cell receptor on the cells from humans, bats, civets, cats, and pigs, but it cannot bind to cells without ACE- 2 . ACE-2 cells were found to be abundantly present throughout the respiratory tract as well as the salivary duct epithelium in the human mouth. ${ }^{21}$

A furin-like cleavage site has been found in the spike protein of the COVID-19 virus. ${ }^{22}$ Furin has been observed to play a role in cleaving the glycoproteins during viral infections, which is abundantly present in the lungs, and could be one of the ways the virus gains entry into the lung tissue. ${ }^{23}$ This furin was also detected during immunostaining of the human tongue epithelium and was upregulated during carcinoma, namely squamous cell carcinoma (SCC). ${ }^{24}$ Along with the expression of ACE-2 and the presence of furin, the tongue might serve as a high risk for the entry of COVID-19 and may increase the risk for SCC once exposed to COVID-19.22,24

Most dental procedures use a high-speed dental handpiece and work with running water and even routine dental prophylaxis procedures use ultrasonic scalers with running water which produces a large amount of aerosol contaminated with the saliva. ${ }^{25}$ As the most common spread of coronavirus is airborne, oral healthcare professionals must be careful because the particles of droplets and aerosols are small enough to move freely in the air for a longer time period, and then it gets fixed on the environmental surfaces of the respiratory tract. ${ }^{26}$ The coronavirus remained viable in aerosols for 3 hours with a reduction in an infection titer from $10^{3.5}$ to $10^{2.7} \mathrm{TCID}_{50}$ per liter of air. ${ }^{27} \mathrm{~A}$ novel coronavirus can persist on metal, glass, or plastic for 9 days, which can be contaminated by aerosol or droplet production. ${ }^{28}$

\section{Precautions to be Taken in Dental Practices}

The following recommendations are based on American Dental Association (ADA) guidelines, ${ }^{29}$ CDC recommendations, ${ }^{30}$ handbook of COVID-19 prevention and treatment, ${ }^{30}$ guidelines for the prevention and control of novel coronavirus in a medical specialty, ${ }^{31}$ guidelines for the use of medical protective equipment in the prevention and control of coronavirus, ${ }^{32}$ Academy of General Dentistry, ${ }^{33}$ guidelines for preparing the workplace for COVID-19 by the Occupational Safety and Health Act of $1970,{ }^{34}$ and guidelines for the diagnosis and treatment of novel coronavirus pneumonia. ${ }^{35}$

Oral healthcare professionals should know how novel coronavirus can spread, how to identify infected patients, and what kind of measures are necessary to protect themselves, other healthcare workers, and other patients. ${ }^{36}$ Even though dentistry is at higher risk for spread, with proper protective measures, the chances of transmission can be reduced to a great extent. A report was published by Meng et al., at the School and Hospital of Oral Stomatology, Wuhan University, Wuhan, Hubei, China, which included 169 staff members treating more than 700 patients since January 24 , with adequate protective measures and strict infection control guidelines. They recorded all dental procedures daily along with patients' and accompanying persons' phone numbers and home addresses. They have also provided online consultations for more than 1,600 patients since February 3. They had not noticed a case of coronavirus infection among staff, which proves the effectiveness of personal protective measures. ${ }^{37}$

On March 16, 2020, ADA requested that all dental nonemergency and elective procedures be postponed as a part of an effort to curb the spread of coronavirus and alleviate the burden on the hospital and emergency department. ${ }^{38}$ Even considering 
emergency treatment, when the patient is in the acute phase of infected disease, is not recommended to visit in this acute febrile phase. If that occurs, the dentist should not treat the patient, but quarantine and report to the infection control department. ${ }^{39}$ Further recommendations added that till this pandemic period is over, every patient, coming to oral healthcare offices, should be evaluated for body temperature with the use of a contact-free forehead thermometer in the first place. American Association of Endodontics published a questionnaire to screen patients with the potential infection of coronavirus or high-risk patients. ${ }^{40}$ The questionnaire included:

- In the past 14 days, have you or any household member traveled to the international area (China, Iran, Italy, Japan, South Korea, and any European country) or anywhere else? If so, please note location:

- In the past 14 days, have you or any household member had any contact with a known COVID-19 patient?

- Have you or any household member have a history of exposure to COVID-19 biologic material?

- Have you had any history of fever in the last 14 days?

- Have you had any respiratory illnesses, such as cough or difficulty breathing, in the last 14 days?

- Urgent Dental Need Question: Do you have uncontrolled dental or oral pain, infection, swelling or bleeding or trauma to your mouth?

If a patient replies "yes" to any of the screening queries but the temperature is below $37.3^{\circ} \mathrm{C}$ or $99.1^{\circ} \mathrm{F}$, the dentist can postpone the treatment until 14 days after the exposure event. The patient should be educated to self-quarantine at his/her home and report to the local health department if he/she develops a fever or flulike syndrome. ${ }^{19}$ If a patient responds "yes" to any of the abovementioned screening queries, but his/her temperature is more than $37.3^{\circ} \mathrm{C}$, the patient should be quarantined with immediate effect, and the dentist should report the case to the infection control department of the hospital or the pertinent health department. If a patient replies "no" to all the questions and his/her temperature is below $37.3^{\circ} \mathrm{C}$, the dentist can treat the patient with extra protection measures and avoid spatter or aerosol-generating procedures to the best. ${ }^{19}$ If a patient replies "no" to all the screening questions, but his/her temperature is more than $37.3^{\circ} \mathrm{C}$, the patient should be advised to go to the designated clinic for COVID-19 testing and further medical care. ${ }^{19}$

ADA has provided guidelines for dental emergencies. Painful swelling in a patient's mouth, bleeding in a patient's mouth that does not stop, pain in a tooth or jaw bone, a gum infection that has swelling or pain, dressing changes or removal of stitches, broken or knocked-out teeth, biopsy or similar diagnostic assay of abnormal tissue, denture adjustment if a patient is receiving radiation or treatment for cancer, and patient's cheek or gums hurt from brace wires are some of the emergencies which should be considered for consultation and procedure with the use of proper personal protective equipment (PPE). ${ }^{41}$

The following outlines the precautions to be taken during the coronavirus pandemic:

- Personal protective measures for dentist and healthcare professionals:

All oral healthcare professionals must wear protective eyewear, face masks (N95), gloves, headcaps, face shields, and protective outwear during the epidemic period of coronavirus. One must monitor and record the health status of all staff in the office and conduct health monitoring that includes measuring body temperature and respiratory symptoms. ${ }^{42}$

- The protocol for donning PPE includes the following sequences. Healthcare professionals should start with putting on special work clothes and work shoes and then wash hands followed by putting on a disposable surgical cap, then wearing a medical protective mask (N95) followed by putting on inner disposable latex gloves and then wearing eyewear. ${ }^{30}$

- Protocol for removing PPE includes first wash hands and remove visible bodily fluids, blood contaminants, etc., on the outer surface of both hands that will replace outer gloves with new gloves, then remove eyewear followed by washing hands, then remove the mask followed by handwashing, and then remove headcap. $^{30}$

- Hand Hygiene: Currently, the rate of compliance for hand hygiene procedures is very poor, reported $40 \% .{ }^{43}$ WHO recommends "five moments of hand hygiene in Dentistry." In this concept, dental healthcare providers should focus on five areas: (1) before touching a patient, (2) before clean/aseptic procedures, (3) after body fluid exposure event, (4) after touching a patient, and (5) after touching the patient's surroundings. ${ }^{44}$ Caution should be taken by dental professionals to avoid touching their own eyes, mouth, and nose. ${ }^{45}$ The United States Environmental Protection Agency recommends using 60\% ethanol and $70 \%$ isopropanol-based hand sanitizer, which are effective to inactivate novel coronavirus. ${ }^{46}$ The novel coronavirus can live under artificial fingernails both before and after using an alcohol-based hand sanitizer and handwashing (CDC). CDC recommends not to keep natural nail tips more than $1 / 4$ inch long. CDC also advised removing any ornaments. Studies have shown that skin underneath rings is found to contain more germs than the areas of the skin on fingers without rings. ${ }^{47}$

- Precautions to be taken in the waiting area: Induction of physical barriers at waiting areas to lessen contact with potentially infectious patients is recommended. Chairs should be a minimum of $6 \mathrm{ft}$ apart in the reception. All articles that cannot be frequently disinfected should be removed from the waiting area, such as magazines, toys, video game controllers, or any other object that may be frequently touched. Reduce the number of patients waiting in the reception. This can be executed by having patients wait in their vehicles or by staggering appointment times. $^{19}$

- Work practice control: After prolonged dental clinic closures and nonuse, dental unit waterline and autoclaves should be evaluated. Water quality and sterilization efficacy should be checked as per the manufacture's guidelines. Water quality should meet the criteria of the EPA for safe drinking water. In the dental setting, provide clinical treatment to one patient at a time when possible. All instruments which are exposed during the procedure are reflected as contaminated, hence clearing all counter spaces for any item. ${ }^{19,28}$

- Engineering control: Consideration should be made regarding the ventilation system, strategic patient placement, and control of patient volume. ${ }^{17,19}$

- Environmental control: As per revised CDC guidelines released on June 17, 2020, it is not necessary to wait for 15 minutes after discharging patients and before reentering the operatory to clean and disinfect the area, if the patient is not suspected of 
being infected with COVID-19. If the patient is established that is suspected of being infected with COVID-19, time intervenes may change depending on the rate of air change per hour of the heating, ventilation, and air-conditioning system. For example, if the facility's rate change per hour is 10, the time required for 99\% efficacy for removal is 28 minutes; for $99.9 \%$ efficacy for removal, the time elapse would be 41 minutes. ${ }^{19,28}$

- Recommendation for reducing aerosols produced during the dental procedure:

Aerosols are produced during all dental procedures which require the use of high- and slow-speed handpiece, ultrasonic scalers. Even in the absence of coolant water, there is aerosolization of material from an operative site with ultrasonic scalers. ${ }^{48}$ Rubber dam is recommended for most dental procedures, as it reduces the production of saliva or blood-contaminated aerosol. ${ }^{49} \mathrm{~A}$ study showed that a rubber dam reduced the airborne particles by $70 \%$ in a $3 \mathrm{ft}$ diameter of the operational field. ${ }^{50} \mathrm{An}$ in vitro study conducted by Dahlke et al. reported that the use of a dental dam with a high-volume evacuation or Isolite system significantly reduced splatter overall compared with the use of high-volume evacuation alone. ${ }^{51}$

The use of mouth rinse has been shown to effectively reduce the bacterial count from the oral cavity. Furthermore, preprocedural mouth rinses with the use of mouthwashes further reduce the number of microorganisms in dental aerosols, which help reduce the risk of contamination in a dental office. ${ }^{52}$ Most commonly, the use of a chlorhexidine (CHX)-containing mouthwash is not effective against novel coronavirus. CDC recommends using $1 \%$ hydrogen peroxide or $0.2 \%$ povidoneiodine mouthwash to reduce the salivary load. ${ }^{53}$

High-speed handpieces without antiretraction valves may aspirate and expel the debris and fluids during dental procedures, which further contaminate air and water tubes within the dental unit and raise the chance of increasing cross infection. The dental handpiece is required to have an approved antiretraction valve, which prevents contaminated fluids, such as saliva, from being suck back into the handpiece. These valves are designed to stop the retraction of resilient, pathogenic bacteria in oral fluids. ${ }^{54}$

All dental patients during this pandemic period should be treated in the negative pressure isolation room with an air filtration device. A difference in pressure causes movement of air from the areas of higher pressure to those of lower pressure. For a dental operatory, the room should be negatively pressurized to prevent infectious particles from escaping the room envelope. ${ }^{55}$ Filtration reduces the risk of transmitting airborne infectious agents. When used correctly, portable high-efficiency particulate air filters are proven to be an effective method for achieving the airborne isolation environment. When properly installed and maintained, filters for clinical spaces should be able to remove at least $90 \%$ of 0.5 microns and larger-size particles from outside and inside air. ${ }^{56}$

Ultraviolet germicidal irradiation is used to control airborne microorganisms and environment surface decontamination. Germicidal lamps give off light at the short end of a wavelength band that is harmful to contaminants. ${ }^{57}$ In a dental operatory, it should be used for 1 hour each time, three times a day. ${ }^{30}$

Disinfection of the floors and walls with $1000 \mathrm{mg} / \mathrm{L}$ chlorinecontaining disinfectant through floor mopping, spraying, and wiping is advised and it should be repeated three times a day. Intermittent disinfection is recommended at any time when there is contamination. From the object surface, visible pollutants should be completely removed followed by wiping the surface with $1000 \mathrm{mg} / \mathrm{L}$ chlorine-containing wipes. Wipe the cleaner surface first and then process to a contaminated surface. ${ }^{30}$ Clinical contact surfaces can be contaminated from patient materials either by direct spray or splatter generated during a dental procedure or by direct contact with the dental healthcare professional's gloved surface. This surface includes light handles, switches, radiograph equipment, chairside computers, drawer handles, reusable container of dental materials, faucet handles, and pens which should be protected using plastics, paper, and other material barriers. Dental handpieces or other intraoral instruments which run through air and use water from the dental units should be cleaned and heat-sterilized. For handpieces, use liquid chemical sterilant or ethylene oxide, but do not just surface-disinfect. ${ }^{58}$

- Teledentistry: Teledentistry is a method for a patient to receive services when a dentist or other oral healthcare provider overseeing the delivery of those services is not in the same physical location as the patient. With teledentistry, there is the use of telecommunication technologies including audio or video calls to convey health information and facilitate the delivery of dental services without physical constraints. It can include patient care, consultations, and public awareness and education, but not limited to live video connections, phone calls, and text messages. ${ }^{59}$ During this pandemic period, teledentistry allows the dentists to identify whether patients are having dental emergencies before they visit the dentist. It can also store patient records, monitor a patient remotely, and advise on preventive therapy, which further reduces dental emergencies. Recently, ADA has launched codes for use as reimbursement while implementing teledentistry. ${ }^{60}$

\section{Discussion}

In the last two decades, we have faced two pandemics due to coronavirus, SARS-CoV (2002) and MERS-CoV (2012). The flare-up of novel coronavirus has become a clinical hazard of the general population and healthcare workers worldwide. However, knowledge and awareness of COVID-19 are still lacking. Antiviral therapy and vaccination are currently in the development phase. Being responsible citizens and healthcare personnel, we must execute belligerent infection control measures to combat the spread. If we know, then only we can respond.

\section{ConCLUSION}

Although the United States, Israel, and China developed a vaccine for this newer disease, it will take a longer time to be effective in action during this epidemic duration because safety testing and clinical trials are still running. What we can do only is strictly adhere to infection control guidelines and a heightened sense of awareness.

\section{Acknowledgments}

The authors want to thank all doctors, nurses, and cleaning staff for fighting against the novel corona pandemic. 


\section{References}

1. Lu H, Stratton CW, Tang YW. Outbreak of pneumonia of unknown etiology in Wuhan, China: the mystery and the miracle. J Med Virol 2020;92(4):401-402. DOI: 10.1002/jmv.25678.

2. WHO Director-General's remarks at the media briefing on 2019-nCoV on 11 February 2020. World Health Organization. 2020. Available from: https://www.who.int/dg/speeches/detail/who-director-general-sremarks-at-the-media-briefing-on-2019-ncov-on-11-february-2020 [Accessed April 2, 2020].

3. Cheng ZJ, Shan JJ. 2019 novel coronavirus: where we are and what we know. Infection 2020;48(2):155-163. DOI: 10.1007/s15010-020-01401-y.

4. Gorbalenya AE, Baker SC, Baric RS, et al. Severe acute respiratory syndrome-related coronavirus: The species and its viruses - a statement of the Coronavirus study group. Nat Microbiol 2020;5:536544. DOI: 10.1101/2020.02.07.937862.

5. Wu Z, McGoogan JM. Characteristics of and important lessons from the coronavirus disease 2019 (COVID-19) outbreak in China: summary of a report of 72314 cases from the Chinese Center for Disease Control and Prevention. J Am Med Assoc 2020;323(13):1239-1242. DOI: 10.1001/ jama.2020.2648.

6. Choe YJ, Choi EH. Are we ready for coronavirus disease 2019 arriving at schools? J Korean Med Sci 2020;35(11):e127. DOI: 10.3346/ jkms.2020.35.e127.

7. Novel Coronavirus (2019-nCoV) situation reports-75. World Health Organization. 2020. Available from: https://www.who.int/ emergencies/diseases/novel-coronavirus-2019/situation-reports [Accessed April 4, 2020].

8. Yu P, Zhu J, Zhang Z, et al. A familial cluster of infection associated with the 2019 novel coronavirus indicating possible person-toperson transmission during the incubation period. J Infect Dis 2020;221(11):1757-1761. DOI: 10.1093/infdis/jiaa077.

9. Holshue ML, Doremalen Nvan, Fauci AS, et al. First Case of 2019 Novel Coronavirus in the United States: NEJM. N Engl J Med 2020;382:929936. DOI: 10.1056/NEJMoa2001191. Available from: https://www. nejm.org/doi/full/10.1056/NEJMoa2001191 [Accessed April 5, 2020].

10. Liu K, Fang Y-Y, Deng Y, et al. Clinical characteristics of novel coronavirus cases in tertiary hospitals in Hubei province. Chin Med J 2020;133(9):1025-1031. DOI: 10.1097/CM9.0000000000000744.

11. Coronavirus (COVID-19). National Institutes of Health. 2020. Available from: https://www.nih.gov/health-information/coronavirus [Accessed April 2, 2020].

12. Clinical management of severe acute respiratory infection when COVID-19 is suspected. World Health Organization. 2020. Available from: https://www.who.int/publications-detail/clinicalmanagement-of-severe-acute-respiratory-infection-when-novelcoronavirus-(ncov)-infection-is-suspected [Accessed April 2, 2020].

13. Chaux-Bodard AG, Deneuve S, Desoutter A. Oral manifestation of Covid-19 as an inaugural symptom. J Oral Med Oral Surg 2020;26(2);18. DOI: $10.1051 / \mathrm{mbcb} / 2020011$

14. Khurshid Z, Asiri FYI, Wadaani HA. Human saliva: non-invasive fluid for detecting novel coronavirus (2019-nCoV). Int J Environ Res Public Health 2020;17(7):2225. DOI: 10.3390/ijerph17072225.

15. Sabino-Silva R, Jardim ACG, Siqueira WL. Coronavirus COVID-19 impacts to dentistry and potential salivary diagnosis. Clin Oral Investig 2020;24(4):1619-1621. DOI: 10.1007/s00784-020-03248-x.

16. Zhu N, Zhang D, Wang W, et al. A novel coronavirus from patients with pneumonia in China, 2019. N Engl J Med 2020;382:727-733. DOI: 10.1056/NEJMoa2001017. Available from: https://www.nejm.org/doi/ full/10.1056/NEJMoa2001017 [Accessed April 5, 2020].

17. Silva-Boghossian CM, Colombo APV, Tanaka M, et al. Quantitative proteomic analysis of gingival crevicular fluid in different periodontal conditions. PLoS One 2013;8(10):e75898. DOI: 10.1371/journal. pone.0075898.

18. Peng X, Xu X, Li Y, et al. Transmission routes of 2019-nCoV and controls in dental practice. Int J Oral Sci 2020;12(1):9. DOI: 10.1038/s41368-0200075-9.
19. Update and interim guidance on outbreak of 2019 novel coronavirus. Available from: https://emergency.cdc.gov/han/han00427.asp [Accessed July 6, 2020].

20. Gorman J. The coronavirus, by the numbers. The New York Times. 2020. Available from: https://www.nytimes.com/2020/03/05/health/ coronavirus-deaths-rates.html [Accessed April 5, 2020].

21. Xu H, Zhong L, Deng J, et al. High expression of ACE2 receptor of 2019nCoV on the epithelial cells of oral mucosa. Int J Oral Sci 2020;12(1):8. DOI: 10.1038/s41368-020-0074-x.

22. Li X, Duan G, Zhang W, et al. A furin cleavage site was discovered in the S protein of the Wuhan 2019 novel coronavirus. 2020. Available from: www.chinaxiv.org/abs/202002.00004.

23. Izaguirre $G$. The proteolytic regulation of virus cell entry by furin and other proprotein convertases. Viruses 2019;11(9):837. DOI: 10.3390/ v11090837.

24. Lopez de Cicco R, Watson JC, Bassi DE, et al. Simultaneous expression of furin and vascular endothelial growth factor in human oral tongue squamous cell carcinoma progression. Clin Cancer Res 2004;10(13):4480-4488. DOI: 10.1158/1078-0432.CCR-03-0670.

25. Cleveland JL, Gray SK, Harte JA, et al. Transmission of blood-borne pathogens in US dental health care settings. J Am Dent Assoc 2016;147(9):729-738. DOI: 10.1016/j.adaj.2016.03.020.

26. Dhama K, Sharun K, Tiwari R, et al. COVID-19, an emerging coronavirus infection: advances and prospects in designing and developing vaccines, immunotherapeutics, and therapeutics. Hum Vaccin Immunother 2020;16(6):1232-1238. DOI: 10.1080/21645515.2020.1735227.

27. van Doremalen N, Bushmaker T, Morris DH, et al. Aerosol and surface stability of HCoV-19 (SARS-CoV-2) compared to SARS-CoV-1. N Engl J Med 2020. DOI: $10.1101 / 2020.03 .09 .20033217$.

28. ADA releases coronavirus handout for dentists based on CDC guidelines. Available from: https://www.ada.org/en/publications/ ada-news/2020-archive/february/ada-releases-coronavirushandout-for-dentists-based-on-cdc-guidelines [Accessed April 2, 2020].

29. How to protect yourself from COVID-19. Coronavirus. Available from: https://coronavirus.dc.gov/page/how-protect-yourself-covid-19 [Accessed April 2, 2020].

30. Handbook of COVID-19 prevention and treatment: the first affiliated hospital, Zhejiang University School of Medicine, Complied according to clinical experience. Hangzhou, China: First Affiliated Hospital, Zhejiang University School of Medicine; 2020.

31. National Health Commission of the People's Republic of China. Technical guide for prevention and control of new coronavirus infection in medical institutions (Second Edition) (2020-01-22). 2020. Available from: https://sudanjem.com/2020/04/protocol-onprevention-and-control-ofnovel-coronavirus-pneumonia/[Accessed 2 April 2020].

32. General Office of National Health Commission. Guidelines for the use of common medical protective products in the prevention and control of pneumonia due to new Coronavirus (Trial). Nhc.Gov.Cn, General Office of National Health Commission. 2020. Available from: www.nhc.gov.cn/yzygj/s7659/202001/e71c5de925a64eafbe.

33. Williams L. The 2019 novel coronavirus and the practice of dentistry. AGD. 2020. Available from: https://www.agd.org/publications-andnews/agd-news-details/2020/02/12/the-novel-coronavirus-and-thepractice-of-dentistry [Accessed April 2, 2020].

34. Guidance on Preparing Workplaces for COVID-19. Available from: https://www.osha.gov/Publications/OSHA3990.pdf [Accessed April 2 , 2020].

35. China Law Translate. New coronavirus pneumonia diagnosis and treatment plan. China law translate. 2020. Available from: https:// www.chinalawtranslate.com/en/coronavirus-treatment-plan-7/ [Accessed April 2, 2020].

36. Spagnuolo G, Vito DD, Rengo S, et al. COVID-19 outbreak: an overview on dentistry. Int J Env Res Public Health 2020;17(6):2094. DOI: 10.3390/ ijerph17062094. 
37. Meng L, Hua F, Bian Z. Coronavirus disease 2019 (COVID-19): Emerging and future challenges for dental and oral medicine. J Dent Res 2020;99(5):481-487. DOI: 10.1177/0022034520914246.

38. ADA calls upon dentists to postpone elective procedures. Available from: https://www.ada.org/en/press-room/news-releases/2020archives/march/ada-calls-upon-dentists-to-postpone-electiveprocedures [Accessed April 2, 2020].

39. Johns Hopkins Coronavirus Resource Center. Available from: https:// coronavirus.jhu.edu/ [Accessed April 2, 2020].

40. Ather A, Patel B, Ruparel NB, et al. Coronavirus disease( COVID 19): implications for clinical dental care. J Endod 2020;46(5):584-595. DOI: 10.1016/j.joen.2020.03.008.

41. ADA develops guidance on dental emergency, nonemergency care. Available from: https://www.ada.org/en/publications/adanews/2020-archive/march/ada-develops-guidance-on-dentalemergency-nonemergency-care [Accessed April 2, 2020].

42. COVID-19. European Centre for Disease Prevention and Control. 2020. Available from: https://www.ecdc.europa.eu/en/covid-19-pandemic [Accessed April 2, 2020].

43. Thivichon-Prince B, Barsotti O, Girard R, et al. Hand hygiene practices in a dental teaching center: measures and improve. Eur J Dent 2014;8(4):481-486. DOI: 10.4103/1305-7456.143629.

44. Ellingson K. Hand hygiene promotion from the US perspective: putting WHO and CDC guidelines into practice. Hand Hygiene 2017:221-229. DOI: 10.1002/9781118846810.CH32.

45. Kwok YLA, Gralton J, Mclaws M-L. Face touching: a frequent habit that has implications for hand hygiene. Am J Infect Control 2015;43(2):112114. DOI: 10.1016/j.ajic.2014.10.015.

46. List N: disinfectants for use against SARS-CoV-2. EPA. 2020 Available from: https://www.epa.gov/pesticide-registration/list-ndisinfectants-use-against-sars-cov-2 [Accessed April 2, 2020].

47. Kadi AA, Salati SA. Hand hygiene practices among medical students. Interdiscip Perspect Infect Dis 2012;2012:1-6. DOI: 10.1155/2012/679129.

48. Harrel SK, Molinari J. Aerosols and splatter in dentistry. J Am Dent Assoc 2004;135(4):429-437. DOI: 10.14219/jada.archive.2004.0207.
49. Harte JA. Standard and transmission-based precautions. J Am Dent Assoc 2010;141(5):572-581. DOI: 10.14219/jada.archive.2010.0232.

50. Samaranayake LP, Peiris M. Severe acute respiratory syndrome and dentistry: a retrospective view. J Am Dent Assoc 2004;135(9):12921302. DOI: 10.14219/jada.archive.2004.0405.

51. Dahlke WO, Cottam MR, Herring MC, et al. Evaluation of the spatterreduction effectiveness of two dry-field isolation techniques. J Am Dent Assoc 2012;143(11):1199-1204. DOI: 10.14219/jada. archive.2012.0064

52. Marui VC, Souto MLS, Rovai ES, et al. Efficacy of preprocedural mouth rinses in the reduction of microorganisms in aerosol. J Am Dent Assoc 2019;150(12):1015-1026.e1. DOI: 10.1016/j.adaj.2019.06.024.

53. Eggers $M$, Koburger-Janssen T, Eickmann $M$, et al. In vitro bactericidal and virucidal efficacy of povidone-iodine gargle/mouthwash against respiratory and oral tract pathogens. Infect Dis Ther 2018;7(2):249_ 259. DOI: 10.1007/s40121-018-0200-7.

54. Live updates: coronavirus and dentistry. British Dental Association. Available from: https://bda.org/advice/Coronavirus/Pages/latestupdates.aspx [Accessed April 2, 2020].

55. Ather B, Edemekong PF. Airborne precautions. 2020. In: StatPearls [Internet]. Treasure Island (FL): StatPearls Publishing; 2020.

56. Klyn SL, Cummings DE, Richardson BW, et al. Reduction of bacteriacontaining spray produced during ultrasonic scaling. Gen Dent 2001;49(6):648-652.

57. Panov V, Borisova-Papancheva T. Application of ultraviolet light (UV) in dental medicine. J Med Dent Practice 2015;2(2):194-200. DOI: 10.18044/Medlnform.201522.194.

58. Guidelines for infection control in dental health-care. Available from: https://www.cdc.gov/mmwr/PDF/rr/rr5217.pdf [Accessed April 2, 2020].

59. Mariño R, Ghanim A. Teledentistry: a systematic review of the literature. J Telemed Telecare 2013;19(4):179-183. DOI: $10.1177 / 1357633 \times 13479704$.

60. ADA COVID-19 coding and billing guidance. Available from: https:// success.ada.org/ /media/CPS/Files/COVID/ADA_COVID_Coding_ and_Billing_Guidance.pdf?_ga $=2.227528157 .1908509749 .1585250053-$ 1025016649.1585250053 [Accessed April 2, 2020]. 